\section{Forest fire hazard recorder}

\section{W. S. PETERSON and T. A. TWEDDLE}

Division of Chemistry

Notional Research Council of Canoda

Ottowo, Ontario

An integrating recorder which is an accurate analogue of the forest floor could be very useful especially when unusual conditions prevail, such as abnormal diurnal cycles in temperature and humidity. A continuous record of the fire hazard or danger would also be very useful to forest protection personnel.

After a careful analysis of the 1940 and 1948 Canadian Forest Fire Danger Tables (Wright and Beall 1940, Beall 1948), D.F. Stedman ${ }^{1}$ designed an instrument which is basically a self-powered mechanical analogue of the forest floor and records a continuous Hazard or Danger Index (Sted${ }^{1}$ Deceased.
L'instrument décrit enregistre continuellement la probabilité d'incendie forestier ou l'indice de danger basé sur les tables de danger d'incendie. forestier de 1940-48 en vigueur jusqu'à tout récemment. II s'agirait du premier appareil enregistreur du genre utilisant deux composantes, afin de simuler le degré d'humidité du tapis forestier. On utilise divers systèmes de façon à transmettre l'eau correctement aux simulateurs durant les périodes de pluie en regard des abaques utilisés. L'auteur propose aussi un appareil beaucoup plus simple bien qu'un peu moins précis qui réduit au minimum les systèmes impliqués dans l'humidification des simulateurs. Un instrument plus complexe serait nécessaire à l'enregistrement de l'indice météorologique des feux de forêts au Canada, durant la période de 1970.

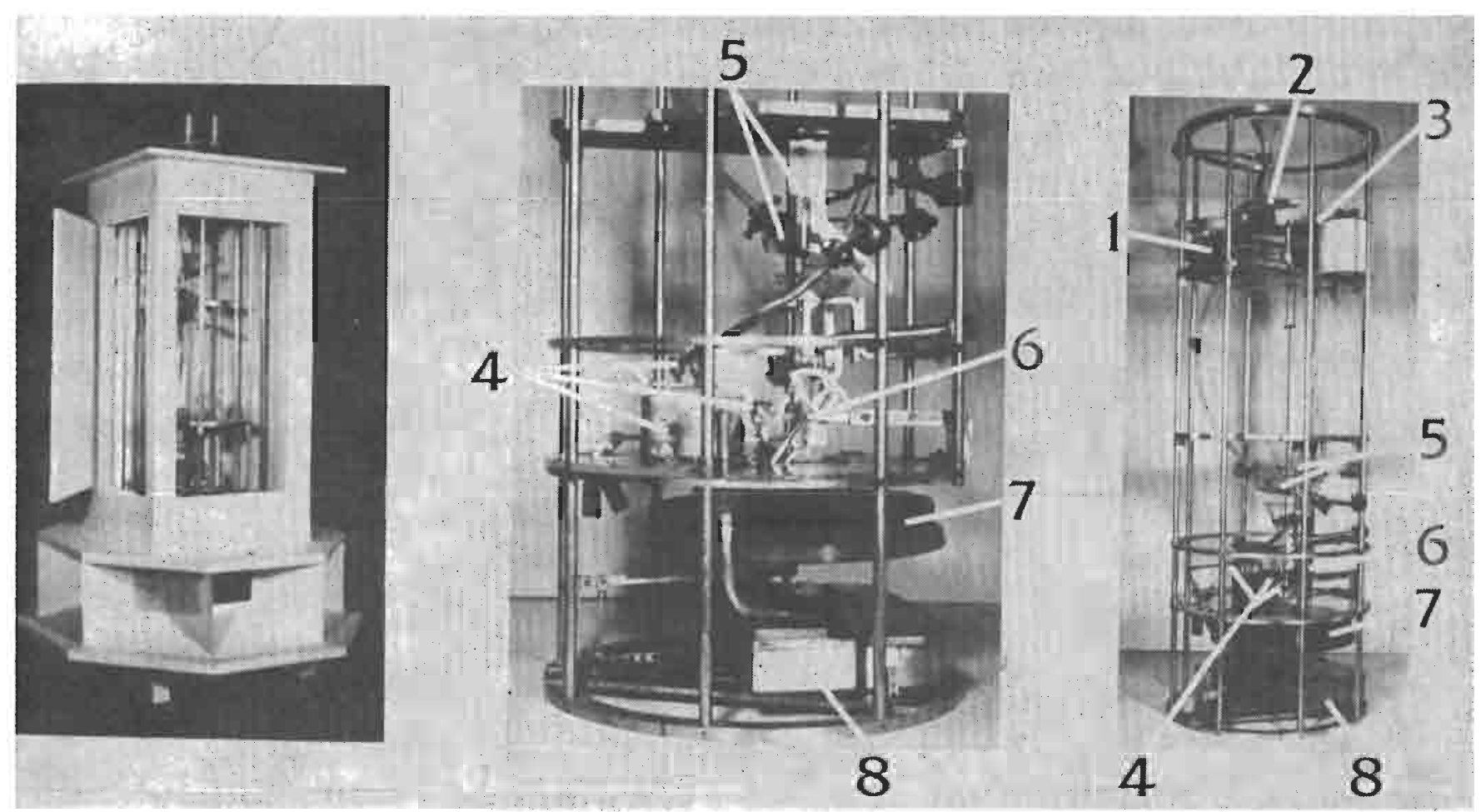

Fig. 1. Forest Fire Hazard Recorder shown set in its enclosure (left), as an overall view (right) and as detail of lower portion (centre). Numbers indicate: 1 spring balance, 2 tipping bucket, 3 filter, 4 varioble divider, 5 -hr timer, 6 wetting curve shift cam, 7 biscuit, 8 drought pan. 
of a pan of water (No. 8) covered with open cell foam plastic. The biscuit and pan weight are measured in the appropriate proportions by a rugged spring balance (No. 1) and recorded by an attached pen on a chart calibrated in the desired units. The instrument also has mechanisms (No. 2, 4 and 6) to distribute a proportion of each rainfall to the two simulators. As in the 1948 rainfall tracer index table, rains separated by more than five hours are treated as separate by means of a "five hour timer" mechanism (No. 5).

A schematic diagram of the instrument is shown in Fig. 2. Rain is caught by a collector (area $1 \mathrm{ft}^{2}$ ) mounted at the top of the instrument enclosure and is split accurately into two streams by a tipping bucket: one stream wets the five hour timer element as it flows to the drought simulator or pan; the other stream flows through a filter to the biscuit ( $\mathrm{Tl}$ simulator) via a proportionator or divider which causes the biscuit to follow the wetting curve of the rainfall tracer index tables (Beall 1948).

The instrument enclosure shown in Fig. 1 (left) allows access of ambient air to the biscuit and pan while at the same time protecting the instrument from the elements.

The biscuit or $\mathrm{Tl}$ simulator is the heart of the instrument. It is a one inch thick wafer made of two layers of wood fibers or chips, the top $20 \%$ red cedar and the rest maple, bonded with a small amount of resin glue.

Some of the results from the 1970 fire season are given. One instrument recorded only Tracer Index (or moisture content of the top fuel layer) while the other recorded Danger Index. The Danger Index could be separated into Tracer Index and Drought Index components from extra data taken from the instrument, so comparison of the behaviour of each simulator could be made with its appropriate table.

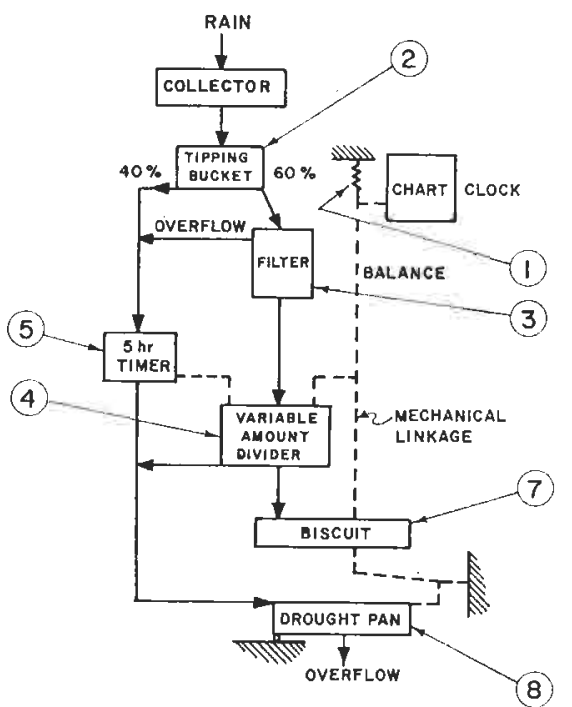

Fig. 2. Schematic of Forest Fire Hazard Recorder Madel A-8.
Tracer Index $-\mathrm{TI}$

Noon weather observations (wind, temperature, rain and relative humidity) are used to predict from the 1948 tables a maximum $\mathrm{TI}$ (equivalent to a minimum moisture content) for the afternoon and these are compared to the afternoon recording of TI by the instruments.

New tables were introduced in 1970 which use essentially three components to arrive at a Canadian Fire Weather Index (Anon. 1970):

Fine Fuel Moisture Code - FFMC

Duff Moisture Code - DMC

Drought Code - DC

The Fine Fuel Moisture Code corresponds closely to the Tracer Index of the 1948 Tables and it was converted to Tracer Index values (FFMC +49 $=\mathrm{TI}$ ).

Comparison of Tracer Index recordings and values calculated from the Tables can be somewhat complicated because firstly the 1948 tables respond to small rains while the 1970 tables respond only to rains 0.03 inches or larger; secondly there can be a wide divergence between the 1948 and 1970 calculated values due to the difference in the way the tables are used, even though the wetting curves are similar in shape. The instrument necessarily started its wetting curve at the $\mathrm{Tl}$ prevailing prior to the rainfall and it was found to follow the 1970 table values except during small rains as noted above. The instrument could however be adjusted to respond only to rains 0.03 inches and greater. The drying rate of the biscuits was found to be adequate under summer wet weather conditions.

During dry weather, the instruments follow the $1970 \mathrm{TI}$ more closely than the $1948 \mathrm{TI}$ and are mainly within 2 units of the values calculated from the tables. Where the error exceeds 2 units, the relative humidity diurnal cycle is somewhat abnormal, e.g. low night humidity or sharply changing humidity following the noon weather readings. Under these conditions the tables would not be expected to predict $\mathrm{Tl}$ accurately because some normalized diurnal cycle would have been used to set up the tables.

After mid September 1970 when fall conditions prevailed, the recorded $\mathrm{TI}$ and the calculated $\mathrm{TI}$ 's diverged from one another. Various factors were responsible for this but are not discussed in this short paper, except to say that the instrument could be adjusted to simulate the 1970 tables faithfully. However, the recorded TI would probably be slightly below the 1970 table values due to the different shape of diurnal humidity cycle in the fall (Cudbird 1964) which effectively reduces the amount of drying each day, over and above the reduction due to lower temperatures.

\section{Drought Index - DRI}

To allow comparison of 1970 Duff Moisture Code (DMC) with the instrument Drought Index and 1948 calculated Drought Index, the value of DMC $/ 3$ was used since it was observed that the average drying per summer day was about 3 units in the 
1970 tables, compared to 1 unit per day for the Drought Index.

During the summer months, it was found that the instrument Drought Index could be made to simulate the 1948 Drought Index and the 1970 $\mathrm{DMC} / 3$ if the foam cover on the Drought pan (Fig. 1. No. 8) was contiguous and a tight fit on the pan. When fall weather arrived the 1948 Drought Index increased (dried) more rapidly than the other two due to the arbitrary increase of one unit per day built into the 1948 tables. The foam covered pan simulated the $1970 \mathrm{DMC} / 3$ adequately in the fall.

\section{Danger Index — DI}

The recorder Danger Index (uncorrected for wind) is not very close to the $1948 \mathrm{Dl}$ predicted by the tables due to two factors. First, the drought pan actually used on the instrument contained several openings and so the evaporation rate was too high during the summer, and second, the biscuit was a close analogue of the 1970 tables rather than the 1948 tables and with both Tracer Index and Drought Index being high the instrument records a high Danger Index (during the summer). A corrected Instrument Danger Index was also calculated assuming that the instrument drought pan dried at the rate of a separately exposed pan with a contiguous, tight foam cover. The correction brought the instrument Danger Index closer to the 1948 DI (during the summer), but the effect of Tracer Index discrepancy remains.

In general the recorder was closer to the 1970 Fire Weather Index than to the 1948 Danger Index except when the 1970 Index was greater than 16 or when small rains affected the recorder Tracer
Index. However, comparisons between the recorder DI and 1970 Index can only be very approximate because of the different scales used, the FWI scale being open ended and the interactions between the three components used to obtain the 1970 Index being different than interaction built into the instrument between Tracer Index and Drought Index. Further, in the present instrument there is no function for Drought Code, the third component used to calculate the $1970 \mathrm{FWI}$.

\section{Further results}

Preliminary tests were performed with a biscuit in a separate enclosure using a single wetting curve starting at Tracer Index 140 from the 1948 tables with no shift to lower curves even when rain started at lower $\mathrm{Tl}^{\prime} \mathrm{s}$. There is some loss of accuracy, mainly during wet weather but the instrument would be considerably simplified resulting in removal of the five hour timer and lock system (Fig. 1, No. 5) and the wetting curve shift cams (Fig. 1, No. 6).

Copies of instrument charts are shown in Fig. 3 with the corresponding weather records during a rainy period for the two recorders; one instrument was recording the Eastern Danger Index and the other Tracer Index. Some records of interest are shown in this figure (see bars) where three periods of night time drying may be noted when $\mathrm{RH}$ was low (June 29, 30 and July 4) and which would not be taken into account by the Tables. As shown by the solid circles, the Tables predict lower danger than occurred. Also seen is a period of biscuit response to $\mathrm{RH}$ just above $\mathrm{TI} 123$ where convective drying changes to adsorption-desorption mechanism (early a.m. July 3 ) showing good correspondence with the forest floor.

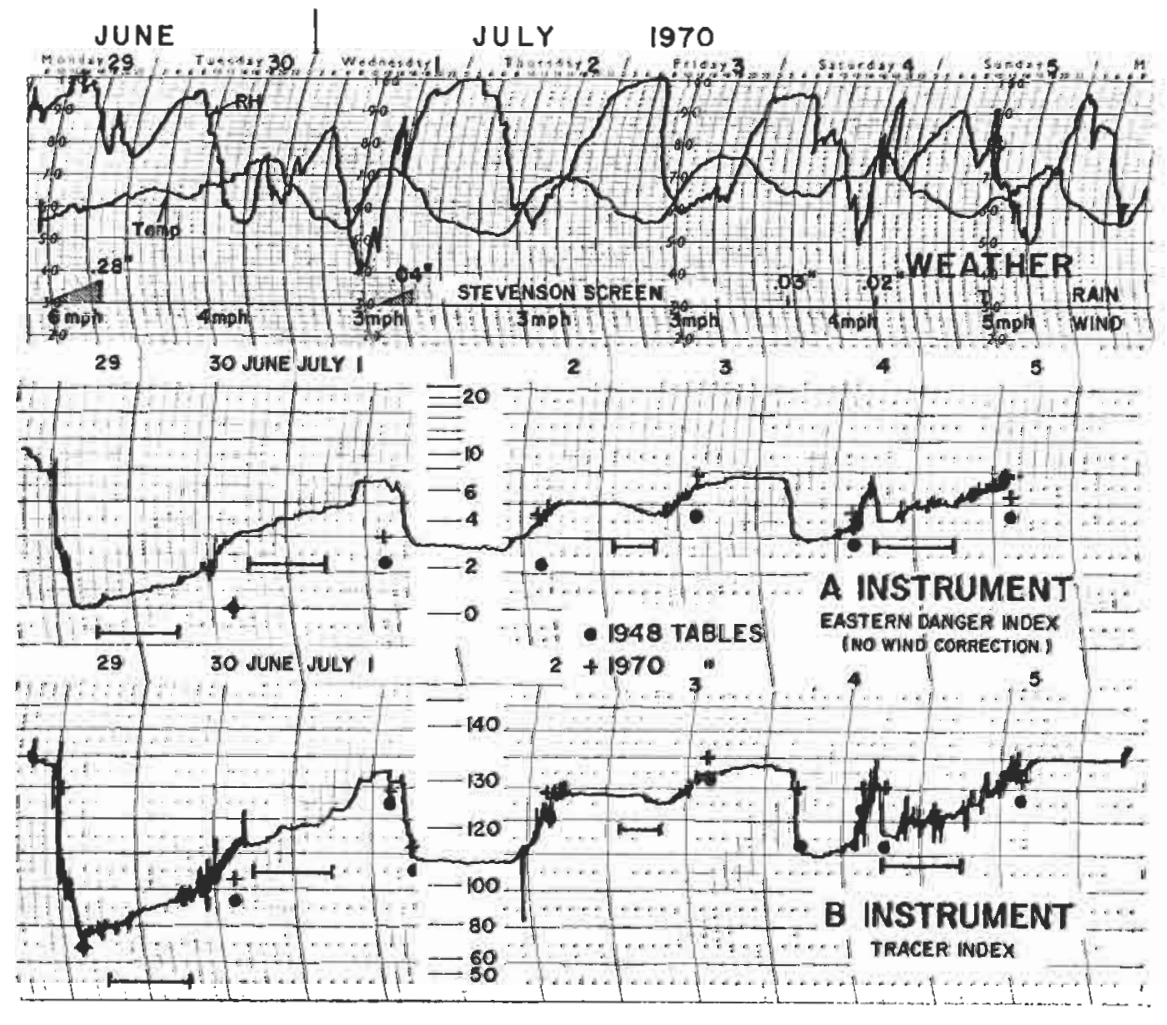

Fig. 3. Comparison of temperature and humidity chart (upper) with Donger Index (lower). Indices calculated from the 1948 Tables are shown on the $\mathrm{DI}$ and $\mathrm{TI}$ grophs. 


\section{Maintenance}

The filter has been the only component requiring regular maintenance. The miniature ball bearings used in many parts have not required maintenance or replacement even after four years; nor has the biscuit performance changed after this time. The prototype instruments used were subjected to rough treatment at times without permanent damage to the various components, but misalignment did occur. For a field instrument various parts would have to be redesigned to minimize interference, misalignment and damage due to rough handling. The instrument height could also be shortened about 10 inches from its present height of 38 inches depending on the mechanisms retained in the final instrument.

\section{Conclusion}

The two components of the instrument used to simulate the forest floor moisture content seem to be adequate for the purpose. While both components were originally designed around the 1948 Tables, the performance of each was almost identical to the improved 1970 Tables except that overwetting occurred in some rains because the instrument had been adjusted to follow the 1948 rainfall Tables. A comparatively simple instrument could be made if only one wetting curve was used, with slight loss of accuracy only under wet conditions.

To make the instrument compatible with the 1970 Tables a new component (simulating Drought Code) would have to be added and some other modifications made, the most important of which would be the interaction between the three components to record the 1970 Fire Weather Index. Wind correction would have to be made on the recorded output of the instrument. These changes would require further development and add considerably to the complexity of the instrument.

The recorder has been tested under various conditions and further information is available from the authors.

\section{References}

ANONYMOUS. 1970. Canadian forest fire weather index. Dep. Fish. and Forest., Can. Forest. Serv.

BEALL, H. W. 1948. Forest fire danger tables (Provisional). Forestry Branch, Ottawa.

CUDBIRD, B. S. V. 1964. Diurnal averages of wind, atmospheric pressure and temperature at selected Canadian stations. Can. Dep. Transport. Met. Br. 4114 C21-33.

STEDMAN, D. F. 1964. Design analysis of forest and grass fire hazard recorders. Nat. Res. Counc., Ottawa. NRC No. C178-64P.

WRIGHT, J. G., and H. W. BEALL. 1960. Preliminary improved forest fire hazard tables for Eastern Canada (with Supplements). Dominion Forest Service, Ottawa. 